\title{
Importance of Free Medical Camps in Exposing Rural Communities' Dental Health Issues and Mitigating Morbidity Associated with Dental Caries
}

\author{
Misigo Dennis Mwala ${ }^{1,}$, Mwongera Moses Kimathi \\ ${ }^{1}$ Department of Microbiology and Parasitology, Kenya Methodist University, Meru, Kenya \\ ${ }^{2}$ Department of Clinical Medicine, Surgery and Community Health, Kenya Methodist University, Meru, Kenya
}

Email address:

dennis.misigo@kemu.ac.ke (M. D. Mwala),dennismisigo@yahoo.co.uk (M. D. Mwala), kimathimwongera@ymail.com (M. M. Kimathi)

\section{To cite this article:}

Misigo Dennis Mwala, Mwongera Moses Kimathi. Importance of Free Medical Camps in Exposing Rural Communities' Dental Health Issues and Mitigating Morbidity Associated with Dental Caries. Science Journal of Public Health. Vol. 3, No. 5, 2015 , pp. $790-796$. doi: $10.11648 /$ j.sjph.20150305.38

\begin{abstract}
Background: The study was conducted at IL-polei in Laikipia North, Kenya. The study aimed at determining the susceptibility to dental caries and oral health status, targeting children and teenagers between the ages of 3-17 years old attending a medical camp in the month of September in 2014. The study was designed as a community based cross-sectional descriptive study where questionnaires were administered to children, the guardians and parents of the children attending the dental section of the medical camp. The clean and verified data was then entered into an Excel computer database and later transferred into SPSS for analysis. Results: A total of 256 children and teenagers were interviewed, medically examined and saliva samples were successful transported to microbiology lab in KeMU. As observed none had a routine visits to a dentist and the practices related to oral hygiene were not satisfactory. The prevalence of dental caries gradually increased with age and those who were highly susceptible to dental caries were teenagers older than 12 years of age (71.9\%). Males had a clinically higher prevalence of caries (75\%) than females. Also noted was that an ancient practice of using stick brushes is still the preferred method of choice for cleaning teeth $(75.6 \%)$. The physical observation of decayed teeth was collaborated by the laboratory findings. Oral health personnel were absent in the rural clinics and dispensaries and hence played no major role $(2.4 \%)$ in educating the community on dental hygiene. Conclusion: we need to strengthen community based dental care services for children and teenagers in IL-Polei and other rural centres with similar characteristics. The study has demonstrated that oral health problems are still predominant in the rural areas where dental services are neglected. In addition, medical camp organisers should also add onto their list of the services, items and activities that will encourage the implementation of good oral health practices because such activities can help in elimination of potential oral health issues before they become a problem and cause future suffering in children.
\end{abstract}

Keywords: Medical Camp, IL - Polei, Oral Health Status

\section{Introduction}

The presence of nutrients, epithelial debris and secretions makes the mouth a favourable habitat for a great variety of bacteria but only a few biofilm-forming and specific acidogenic species of bacteria are believed to cause dental caries [1-3]. Early childhood dental caries is a common infectious disease frequently arising not only because of the microbes responsible but more importantly due to barriers associated with lack of access to oral healthcare services in vulnerable populations with limited resources [19]. The outcome eventually results in a negative impact on the health of children in subsequent years which usually extends beyond the oral cavity and may negatively affect the general well-being of the child $[1,4]$. This study was conducted in a rural hard to reach area in Kenya identified as Il-Polei in Laikipia North, a region inhabited by nomadic pastoral communities, to assess the prevalence of dental caries in subjects attending a medical camp in 2014 organised by the Kenya Methodist University, School of Medicine and Health Sciences in collaboration with the sub-county community health officers through the Ministry of Health Services. This was partially in response to observations made in 2004, that there was scanty data on 
rural prevalence of dental carries in Kenya as most reported studies were clustered around urban town centres [5]. Moreover, currently available data does not address the issues of whether or not dental problems are declining or increasing in Kenya. In addition, the study aimed to demonstrate the importance of medical camps in addressing certain neglected rural health issues more specifically oral health problems in recognition of the fact that improving access to dental services to the neglected would be imperative in addressing the growing need for dental health services by rural communities.

\section{Materials and Methods}

\subsection{Study Area and Design}

The project was a cross-sectional descriptive study by design carried out at IL-Polei in Laikipia North, Kenya.

\subsection{Target Population and Sample Size}

The study population was children and teenagers between the ages of 2-17years old who were attending the medical camp. The exclusion criteria were based on individual being below or exceeding the indicated age limit (2-17yrs) plus also children of non-consenting guardians.

The sample size consisted of 256 participants calculated by the statistical formulae suitable for prevalence study design [6]. We estimated it to be at $63 \%$ which gave as the expected proportion (P) value of 0.63 and we also considered a confidence interval (CI) of $95 \%$.

\subsection{Data Collection Techniques}

A structured questionnaire was designed to collect data on age, sex and gender. The data capture sheet was clear and simple to allow for minimal potential errors from the researcher and the parents. In general the questionnaire had questions testing the participants' knowledge on dental caries and signs and symptoms of dental plaque. In addition, information on their practices as related to dental hygiene, perception of the causes and socio-economic characteristics was obtained using the same questionnaire.

\subsection{Specimen Collection for Microbiological Investigation}

All the children and teenagers were requested to chew parafilm for 3 minutes without swallowing the saliva and their saliva collected in a sterile tube. This saliva was collected early in the morning on the day the medical camp was conducted. The specimens were then transported on ice to the Kenya Methodist University Microbiology laboratory for culturing and screening using the Snyder test technique.

\subsection{Physical Oral Examination}

The children's mouth was also examined for evidence of dental caries (missing, decayed and filled teeth) by a dentist assigned to the medical camp.

\subsection{Snyder Test}

The Snyder test was performed to compare the physical evidence of tooth decay and laboratory indicators of susceptibility by measuring the activity of bacteria in the mouth [22]. The saliva was mixed well for 3 minute, and then a tube of Snyder glucose agar was melted and cooled to $50^{\circ} \mathrm{C}$. $200 \mu \mathrm{l}$ of saliva was then pipetted into the tube with agar and immediately mixed by rotating the tube. The agar was allowed to solidify in the tube, and then incubated at $37^{\circ} \mathrm{C}$. The colour changes that arose after 24,48 and 72 hours of incubation were recorded and interpreted based on the appearance of a range of a colour from green to deep yellow.

\subsection{Data Analysis and Statistical Analysis}

The responses acquired from the questionnaires were first entered into an excel database, then all the data was transferred to the SPSS computer software version 20 for analysis.

\subsection{Ethical Considerations}

Permission to carry out this research was sought and granted by the Kenya Methodist University Medical Camp Organizing Committee. Consent to interview the children and teenagers were also obtained from their parents or guardians who had accompanied them to the medical camp. The demographic information that was gathered was kept confidential and with no identifiers because the subjects names were not asked and their saliva specimen were only identifiable by laboratory codes. Since the saliva collection was a non- invasive method it poised no risk to the participants.

\section{Results}

\subsection{Age Distribution of Subjects Examined}

Seventy eighty percent (78\%) of children who attended the camp were between 12 and 17 years of age and the remaining percentage was composed on children younger than eleven years but not less than 6 years old, none of the children younger than six years presented themselves for dental examination. The majority of participants aged 12-17 years were boys $(93.3 \%)$ even though more girls formed the 6-11 year age group (42.9\%). Using the physical evidence, the prevalence of dental carries in 6-11 year olds was $88.9 \%$ and $93.8 \%$ in $12-17$ year olds. By the laboratory assay (synder test) it was $66.7 \%$ in $6-11$ olds and $71.9 \%$ in $12-17$ year olds. A summary of comparison by gender of the items most frequently used for brushing, knowledge on tooth decay, the physical and laboratory evidence of dental carries can be deduced in the Table 1 and 2.

\subsection{Knowledge on Tooth Decay}

Generally, in the entire study there was no significant difference in the number of females and males with knowledge on tooth decay ( $51.2 \%$ and $48.8 \%$ respectively). 
$85.4 \%$ of children said that they brushed their teeth and only $51.2 \%$ knew they have tooth decay mainly through aching teeth $(43.9 \%)$, only $2.4 \%$ had been advised on their bad teeth by a health personnel. On average the population that was aware of tooth decay composed of only $51.2 \%$ but among those with knowledge the female child had better knowledge (57.1\%) compared to the $45 \%$ of the males. Out of the all subjects observed only $7.3 \%$ had no physical evidence of tooth decay, majority $(92.7 \%)$ had evidence of decaying teeth. The younger children (6-11yrs) were generally less informed and had no information that they have bad teeth (55.6\%). Saliva samples of the older children provided more laboratory evidence of tooth decay though this was not significantly different from the younger ones $(71.9 \%$ and $66.7 \%$ respectively).

\subsection{Signs of Tooth Decay vs. Item Used for Brushing Teeth}

Physically, decayed teeth were observed in $92.9 \%$ of the subjects, the female subjects who visited the medical camp were most affected (95.2\%). However the laboratory evidence contradicted the physical observation were the synder test demonstrated that only $70.7 \%$ of subjects were highly susceptible, mainly being males $(75 \%)$, this was more than the outcome for females by about $7 \%$. In general $92.7 \%$ and $70.7 \%$ of the children were highly susceptible by physical examination and laboratory evidence respectively. Physical signs of tooth decay were observed in $86.8 \%$ of those who brushed their teeth. Among the ones with physical signs of tooth decay $78.9 \%$ of the individuals were those who were using the stick to clean their teeth, $18.4 \%$ of those using toothpaste and in only $2.6 \%$ of those using only water to rinse their mouth. Interestingly physical signs were absent in $66.7 \%$ of those that used only water and absent in $33.3 \%$ of those using sticks. These observations were statistically significant (P: 003). $73.7 \%$ of those with physical evidence of tooth decay were highly susceptible to tooth decay by laboratory evidence, those without a signs had equally susceptibility at $33.3 \%$ of being on both the extreme ends.
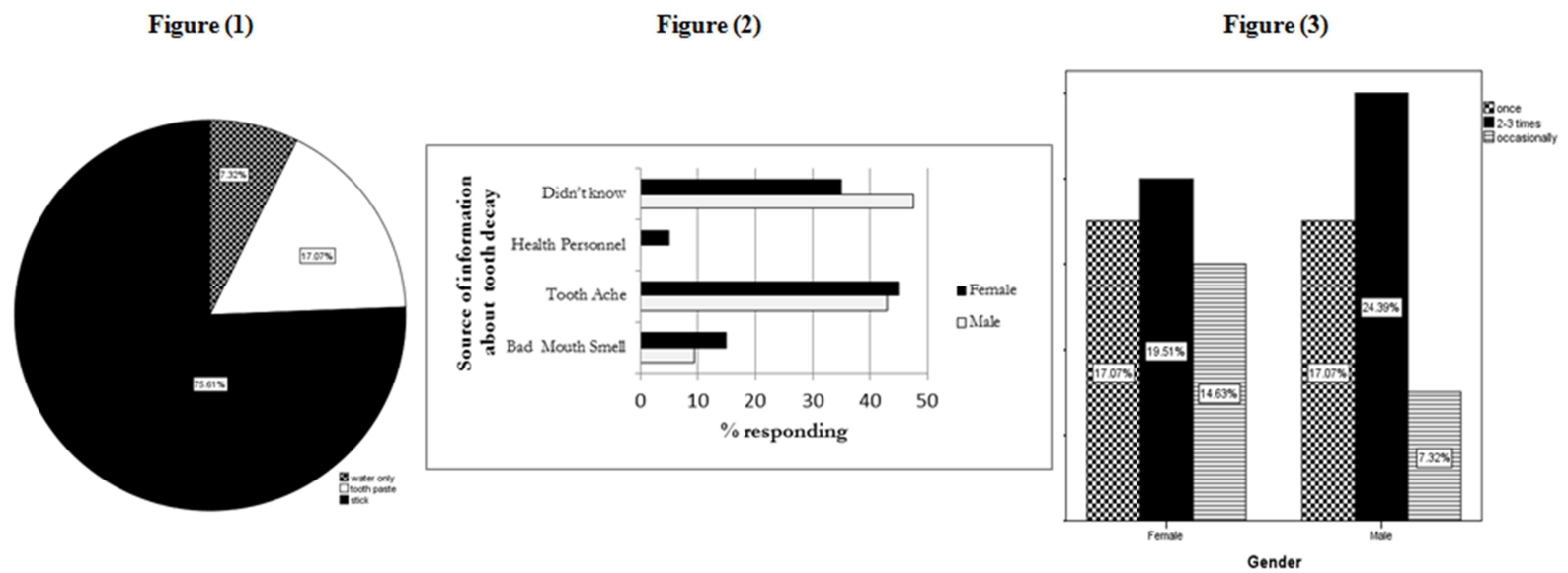

Figure (1). a pie showing the stick as the most preferred tool for brushing, (Fig. 2) a bar graph demonstrating the source of knowledge about tooth decay as observed often information was acquired through self-diagnosis rather than medical assistance by the health personnel, (Fig. 3) a bar graph comparing the frequency of brushing teeth between males and females.

Table 1. Comparison of knowledge, sources of information on tooth decay, physical evidence and laboratory evidence of susceptibility to dental carries by gender.

\begin{tabular}{|c|c|c|c|c|c|c|c|c|c|c|c|c|}
\hline \multirow[b]{2}{*}{ Gender } & \multicolumn{3}{|c|}{$\begin{array}{l}\text { Item used for } \\
\text { brushing (\%) }\end{array}$} & \multirow{2}{*}{$\begin{array}{l}\begin{array}{l}\text { Physical signs of } \\
\text { tooth decay }(\%)\end{array} \\
\text { Signs Present }\end{array}$} & \multicolumn{3}{|c|}{$\begin{array}{l}\text { Laboratory evidence of } \\
\text { Susceptibility (\%) }\end{array}$} & \multirow{2}{*}{$\begin{array}{l}\text { Knowledge of Tooth } \\
\text { Decay (\%) }\end{array}$} & \multicolumn{4}{|c|}{ Subjects Symptoms (\%) } \\
\hline & $\begin{array}{l}\text { Water } \\
\text { Only }\end{array}$ & $\begin{array}{l}\text { Tooth } \\
\text { paste }\end{array}$ & Stick & & Least & Moderate & Highly & & $\begin{array}{l}\text { Bad } \\
\text { Smell }\end{array}$ & $\begin{array}{l}\text { Tooth } \\
\text { Ache }\end{array}$ & $\begin{array}{l}\text { Health } \\
\text { Personnel }\end{array}$ & $\begin{array}{l}\text { Didn't } \\
\text { know }\end{array}$ \\
\hline Female & 4.8 & 19 & 76.2 & 95.2 & 4.8 & 28.6 & 66.7 & 57.1 & 9.5 & 42.9 & 0 & 47.6 \\
\hline Male & 10 & 15 & 75 & 90 & 10 & 15 & 75 & 45 & 15 & 45 & 5 & 35 \\
\hline Av. $\%$ & 7.3 & 17.1 & 75.6 & 92.7 & 7.3 & 22 & 70.7 & 51.2 & 12.2 & 43.9 & 2.4 & 41.5 \\
\hline
\end{tabular}

Av\% (Average percentage)

Td (Tooth decay)

Table 2. Comparison of genders influence on brushing habits and frequency of brushing teeth

\begin{tabular}{|c|c|c|c|c|c|c|c|c|c|c|c|}
\hline \multirow[b]{2}{*}{ Gender } & \multicolumn{2}{|c|}{$\begin{array}{l}\text { Age Group in } \\
\text { Years (\%) }\end{array}$} & \multirow{2}{*}{$\begin{array}{l}\begin{array}{l}\text { Brush Teeth } \\
\text { (\%) }\end{array} \\
\text { Answered yes }\end{array}$} & \multicolumn{3}{|c|}{ Frequency of Brushing (\%) } & \multicolumn{5}{|c|}{ Brushing Time (\%) } \\
\hline & $6-11$ & $12-17$ & & Once & $\begin{array}{l}\text { 2- } \\
\text { 3times }\end{array}$ & Occasional & Morning & Midday & Evening & Morning \& Evening & all \\
\hline Female & 33.3 & 66.7 & 85.7 & 33.3 & 38.1 & 28.6 & 38.1 & 0 & 0 & 28.6 & 33.3 \\
\hline Male & 10 & 90 & 85 & 35 & 50 & 15 & 10 & 20 & 5 & 30 & 35 \\
\hline Av. $\%$ & 22 & 78 & 85.4 & 34.1 & 43.9 & 22 & 24.4 & 9.8 & 2.4 & 29.3 & 34.1 \\
\hline
\end{tabular}




\subsection{Item Used for Brushing vs. Frequency of Brushing}

A toothbrush and toothpaste was used only by $17.1 \%$ of the subjects, mostly the stick was used by $75.6 \%$ of the children to clean their teeth (see figure 1). The number of males to females using the stick was equal (See Table $1 \& 2$ ). $71.4 \%$ of those who brushed their teeth $2-3$ times were those using toothpaste, but the toothpaste users only formed $17.1 \%$ of studied population. The frequency of brushing teeth seemed to be evenly distributed in young children at $33.3 \%$, but the older children seemed to brush their teeth much frequent, 2-3 times a day (46.9\%). Many respondents who occasionally $(66.7 \%)$ cleaned their mouth were those using only water. This makes water only as the second most used item. Among the stick users $41.9 \%$ used it 2-3times a day and $38.7 \%$ consistently used in it only once in a day. Also observed was that $44.7 \%$ of those with physical signs of tooth decay were actually those who brushed their teeth 2-3 times a day. The laboratory evidence suggests that those highly susceptible were those who brushed their teeth once a day $(78.6 \%)$, followed by those brushing occasionally (66.7\%) and 2-3 times (66.7\%).

\section{Discussion}

\subsection{Gender and Age of the Participants}

It was observed that majority of the participants were males despite wide spread publicity of the event by the community health workers. In most medical camps it is women and children who participate than men. One possible explanation for the observed difference at this medical camp site could be that this being mainly Maasai and Samburu dominated community; the females especially the teenagers were left in the homesteads to take care of the young ones, cook and perform the house works. While the boy child was mainly engaged in animal grazing, perhaps the teenager males were looking after the animals around the area we had gathered for a medical camp, which then meant that they got an opportunity to participate in the study as opposed to their sisters and other female relatives.

Majority of those who participated (both male and female) were between twelve and seventeen years old, these were teenagers who were so curious about activities around the camp site and the group also included an influx of students from two neighbouring high schools. Followed by those in the age group six to eleven years, these were young children who could walk and follow their parents to the medical camp and primary school children. The age group with the least participants was the one with children between the ages of two and five years who, in our observation, were very young children probably left in the homestead with females due to their young age.

\subsection{Overall Susceptibility to Dental Caries}

Although previously dental caries was reported as declining globally in adult population the trend seems to be reversing [7], the caries prevalence in younger ones has not shown a significant decline. Most of the Kenyan surveys have targeted the adult population for measurement of dental caries $[8,9]$. But even those done in children targeted the urban population [10-12]. The present study among children and teenagers at IL-Polei showed that nomadic communities are highly susceptibility to dental caries.

According to American Academy of Dentistry, the first visit to a dentist should be at one year of age and all children should have at least two routine visits to a dentist each year. In this study population a large percentage of children and teenagers had never been to a dentist. This confirms that children in IL-polei do not get adequate dental care and are hence highly susceptible to dental caries. Results of this study emphasize the importance of strengthening community based dental care services for children and teenagers in ILPolei and other rural centres with similar characteristics.

Moreover, high prevalence of dental caries seen in children and teenagers in this community may be due to a number of factors making them be disadvantaged and these may include, the high illiteracy rate, poverty, limited access to oral health services, lack of oral health awareness and the shortage or lack of community oral health workers and other related oral health specialities.

\subsection{Dental Caries and Age Group}

At IL-Polei, children and teenagers were highly susceptible to dental caries; majority of them laid in the age brackets of twelve to seventeen years. This is the period is whereby most of them are developing the second molar and third molar without full chewing function but with highly carious susceptible fissure on mesial surfaces. In addition, during this age group period, there are varied dietary and oral hygienic habits [13]. As children grow older to teenagers; their diet pattern alters, from home-made nutritious food e.g. milk and meat to unhealthy biscuit snacks and sweets easily available at shopping centres. Additional parenteral involvement in modern tooth-brushing practices, a practice that is particularly more common in urban areas than in such a rural set up, is completely lucking. Instead children and teenagers emulate the stick chewing practice which they are nurtured with. It is expected that in this century such acts would fade away but in some rural Kenyan communities especially in the nomadic community this is still happening.

With regard to gender and susceptibility to dental caries, among children and teenagers tested, the rate was clinically higher in males than in females. The difference in the susceptibility rate in males and females could perhaps be an indicator that females are more conscious about their oral health and hygiene as also reported by Lopez et al., [21]. As cultural practice teenager males often are taken from schools to join the morans hence lacking health education on oral hygiene which is incorporated in some subjects at certain levels in the school syllabus. However, since there was no gender discrimination against the female child in IL-polei in 
matters related to schooling, there must be a social economical factor and poor personal oral hygiene habits responsible for the observed tooth decay cases in the females.

The observation that few girls had tooth issues in comparison to the boys may offer an opportunity to explore the role women can play in reducing tooth decay in such a society considering the important roles mothers play in a child's life, where venerability to health problems is high, by educating them more on healthy oral habits which they can in term pass down to the growing children [17].

\subsection{1tems Used to Clean Teeth}

The results revealed that about seventy nine percent of children and teenagers used only sticks to brush their teeth and various reasons could explain why this practise is preferred in this community. First of all, the community believes that the sticks lopped off from a variety of particular non-toxic shrubs and trees (e.g. Olea Africana) around this area have some medicinal substances which whitened and strengthened their teeth even although their physiological and antibacterial property has not yet been proven. Mostly, the sticks used only remove and reduce the number of plaques mechanically [14]. Some miswaks (stick brushes) as reported by other authors seem to have important active ingredients [1]. Secondly, due to the remote location and poverty in IL-Polei the communities' ability to access toothbrushes and toothpaste would be a problem and not part of their households' goods budget, and this could also explain why a certain percentage also just used only water to rinse their mouth. Lastly, IL-polei is inhabited by pastoralists, who move from one place to another and the only item along the way on their journey are sticks from various shrubs which are readily available for free. This has led clinically to poor dental hygiene hence high prevalence of dental caries in this community. This observation is contrary to what was concluded after studying the nomadic Rendile and Samburus tribes in Kaisut area [15]. Note that the usage of unconventional and some natural products to clean the teeth is a practice similarly observed in India, Saudi Arabia and many other African countries $[1,16]$ where in addition items such as ash, coal and manjan have been used. Even then, there seem to be conflicting information on the efficacy of stick brushes but in many observations the individuals exposed to these practice still suffer the consequences of such practices, tooth decay, the same was observed in this study.

\subsection{Frequency of Cleaning Teeth}

Effective brushing is known to remove dental plaques, which is the first step in dental decay and as further highlighted by the American dental associations, brushing teeth twice a day is an important mode of preventing dental caries. A high percentage of the children and teenagers said they brush their teeth, yet tooth decay was obvious in the same individuals, this shows despite majority of the participant claiming to be brushing their teeth, they either did not use the right items to brush them or they did not brush their teeth frequently as expected or they did not brush them well hence contributing to poor oral hygiene and high prevalence of dental caries in the community. Irrespective of the item used to clean their teeth (stick or commercial brush) majority of the children and teenagers $(53 \%)$ said that they brush their teeth once a day. The fact that this children showed some initiative to brush their teeth despite lucking the essential modern tools to use, demonstrated the potential that allocation of necessary items may have to alleviate dental caries. The area has several schools around but it was noted that lessons in basic home sciences where personnel hygiene is emphasized were poorly conducted.

\subsection{Availability of Dentist and Dental Technologists}

Dental caries is considered as one of the most common health problems and has been shown to be more prevalent in children worldwide [20]. In Kenya, the prevalence rate of dental caries is estimated to be between $57 \%$ and $63 \%$ in children (National Oral Health Policy, 2000). In Il-polei community, which is poor, disadvantaged, and socially marginalized, the situation is particularly severe; this is because the priority given to oral health is low because of budgetary constraints and a multitude of other pressing health problems. In this area, access to oral health facilities and trained oral health manpower is severely limited with no dentists, dental technologists and community oral health officers in rural clinics and dispensaries. This confirms a 2004 report [5] which reviewed the status of oral health services in Kenya and vividly revealed that $80 \%$ of the dentists within the country were observed to be operating in urban centres.

\subsection{Teachers' Role in Oral Health Hygiene}

Perhaps the focus should shift to using teachers to reinforce the importance of oral hygiene. This is because teachers can instil in children important attitudes and skills that are remembered for a long period of time, considering that they seem to be spending more time with them as was similarly observed by [17]. However the challenge would still remain where there is high drop out of school and lack of resources to purchase and practice modern tooth brushing.

\subsection{Free Medical Camps}

Free medical camps provided to communities, organized by both local health personnel and also in partnership with their collaborators, are increasingly becoming an important and positive feature that is developing in Kenya. Even though theirs is no proper record and statistics of the number of medical camps organised in Kenya but an online wide-web search of the number organised just in the year 2014 seem to suggest that most of them are being organised by some parastatals (Kenya Airways), Universities, nongovernmental organisations such as Medical Assistance 
Program (MAP), Medecins sans Frontires (MSF), CARE, Rotary Club, Lions Club and Jigger-ahadi. Also by the faith-based institutions like the Kenya Methodist University (KeMU), Jesus freese ministries, and even insurance companies (Association of Kenya Insurance).Often the medical camps provide a wide range of services mostly screening, treating, educating and referring patients were necessary, but some may be very specific on the kind and nature of conditions targeted during the camps. Most of them target malaria control, malnutrition, reproductive health issues, diabetes. Recently some parasitic helminths and entomological infections like jiggers are becoming a popular inclusion in such activities. As a result medical camps despite being sporadic are becoming an important component of the national health system and are readily acceptable by the communities especially those located in financially and personnel starved areas. It is our observation that these free medical camps not only provide immense opportunities to serve the community but they also provide avenues to collect important data that can be used for policy development, and as such they should be utilized more for applied community-based beneficial research activities.

\subsection{Summary}

In conclusion, good oral hygiene is an essential component of good oral health. Simple oral hygiene activities performed on a day-to-day basis can reduce one's susceptibility to dental caries without any additional cost. In IL-polei community poor oral hygiene has contributed to the high prevalence of dental caries as demonstrated in this study. While dental caries seem to be declining globally in adult population in comparison to the younger ones, in most rural set ups in developing countries the incidence and prevalence still remains high in all populations, and individuals in IL polei community were not exceptional. Using IL-polei as model to understand the magnitude of the problem, it is evident that medical camps activities in the counties should also ensure that their medical camp activities and packages have essential items to educate and mitigate incidence of dental caries by targeting the young ones because the outcome in adults is due to long-term failure to contain the accumulation of microbes consider as normal flora of the buccal cavity in childhood, and also neglecting oral health education for the community as well.

\section{Acknowledgement}

This project got partial support from the Kenya Methodist University through funds to the Medical Camp Organizing Committee and individual contributions. We wish to thank the Kenya Methodist University, School of Medicine and Health Sciences, and the Medical Camp Organizing Committee for granting us permission to attach undergraduate students to collect data for the project. Special thanks to Jason Ireri and Amina Karnen and Nancy Ngima for Technical assistance in the laboratory.

\section{References}

[1] Almas, A. K. and K. Almas, Miswak (Salvadora persica chewing stick): the natural toothbrush revisited. Odontostomatol Trop, 2014. 37(145): p. 27-39.

[2] Forssten, S. D., M. Bjorklund, and A. C. Ouwehand, Streptococcus mutans, caries and simulation models. Nutrients, 2010. 2(3): p. 290-8.

[3] Forrai, J., Dental aspects of general symptoms in the 18th century. Orv Hetil, 2009. 150(21): p. 979-83.

[4] Kenney, M. K., M. D. Kogan, and J. J. Crall, Parental perceptions of dental/oral health among children with and without special health care needs. Ambul Pediatr, 2008. 8(5): p. $312-20$.

[5] Kaimenyi, J. T., Oral health in Kenya. Int Dent J, 2004. 54(6 Suppl 1): p. 378-82.

[6] Bagramian, R. A., F. Garcia-Godoy, and A. R. Volpe, The global increase in dental caries. A pending public health crisis. Am J Dent, 2009. 22(1): p. 3-8.

[7] Ngakinya, N. M., et al., Periodontal health status of patients attending Diabetic Clinic at Kenyatta National Hospital, Nairobi, Kenya. Indian J Dent Res, 1997. 8(4): p. 105-10.

[8] Ngatia, E. M., et al., Nutritional and oral health status of an elderly population in Nairobi. East Afr Med J, 2008. 85(8): p. 378-85.

[9] Kaimenyi, J. T., et al., Oral hygiene habits and dental health awareness of Kenyan children aged 9-15 years in a peri-urban and urban school. East Afr Med J, 1993. 70(2): p. 67-70.

[10] Masiga, M. A., Presenting chief complaints and clinical characteristics among patients attending the Department of Paediatric Dentistry Clinic at the University of Nairobi Dental Hospital. East Afr Med J, 2005. 82(12): p. 652-5.

[11] Owino, R. O., et al., Dental caries, gingivitis and the treatment needs among 12-year-olds. East Afr Med J, 2010. 87(1): p. $25-31$

[12] Moynihan, P. and P.E. Petersen, Diet, nutrition and the prevention of dental diseases. Public Health Nutr, 2004. 7(1A): p. 201-26.

[13] Ndung'u, F. L., et al., A comparative study of the efficacy of plaque control by a chewing stick and a tooth brush. East Afr Med J, 1990. 67(12): p. 907-11.

[14] Carl, W. and J. J. Zambon, Dental health of the Rendille and Samburu of the northern frontier district of Kenya. N Y State Dent J, 1993. 59(6): p. 35-9.

[15] Halawany, H. S., A review on miswak (Salvadora persica) and its effect on various aspects of oral health. Saudi Dent J, 2012. 24(2): p. 63-9.

[16] Chandrashekar, B. R., et al., The use of school teachers to promote oral hygiene in some secondary school students at Hyderabad, Andhra Pradesh, India: A short term prospective pilot study. J Family Community Med, 2012. 19(3): p. 184-9.

[17] National Oral Health Policy and Strategic Plan 2002 - 2012 document, June 2000, Kenya. 
[18] Buddiga V, Gupta B, Aravind K, Reddy MV, Kumar RN, Ashwin D. The comparison of oral health problems with other health problems in urban school children of 10-14 years: A group screening. J Int Oral Health, 2014. 6(5):p.77-80.

[19] Datta P, Datta PP. Prevalence of Dental Caries among School Children in Sundarban, India. Epidemiol, 2013. 3: p.135.
[20] López-Valverde A, Montero J, Camañas G, Peralta B, Gómez de Diego R. Oral Health Habits in Primary and Secondary School Children. OHDM, 2014.13 (4):p. 1076.

[21] Tamgadge Sandhya, Tamgadge Avinash, Evie Satheesan. Caries Activity Indicators: Guide for Dental Practitioners. International Journal of Oral \& Maxillofacial Pathology, 2012. 4(1):p.34-42. 